\title{
Temporal Lobe Metabolic Differences in Medication-Free Outpatients with Schizophrenia via the PET-600
}

Thomas E. Nordahl, M.D., Ph.D., Natalia Kusubov, M.T.(A.S.C.P.), Cameron Carter, M.B.B.S., Shahriar Salamat, M.D., Ph.D., Anne M. Cummings, M.D., Linda O'Shora-Celaya, R.N.C., Jamie Eberling, Ph.D., Lynn Robertson, Ph.D., Ronald H. Huesman, Ph.D., William Jagust, M.D., and Thomas F. Budinger, M.D., Ph.D.

Regional cerebral glucose metabolic rates ( $r C M R g l c)$ were compared in 18 unmedicated outpatients with schizophrenia and 11 normal controls using high resolution positron emission tomography (PET) and the tracer [F-18]2-fluoro-2D-deoxyglucose (FDG). From previous work we expected to see abnormal hippocampal $r C M R g l c$ in the patients, but no striatal abnormalities. Trial-by-trial Stroop cognitive task, which has been shown to activate the anterior cingulate, was performed within a day of the PET study. As our patients performed abnormally on the Stroop we tested for a correlation between the anterior cingulate rCMRglc and Stroop performance. We found no whole slice cortical average glucose metabolic abnormalities. As predicted we found abnormally decreased left hippocampal $r C M R g l c$ in the patients. No striatal or cingulate $r C M R g l c$ abnormalities were noted in patients, but they demonstrated a highly positive correlation between anterior and cingulate $r C M R g l c$ and Stroop facilitation. Patients with higher Stroop interference had more prominent hippocampal metabolic decreases. These localized temporal lobe abnormalities could account for some of the patient's positive symptoms and are consistent with recent findings in the literature. (C) 1996 American College of Neuropsychopharmacology [Neuropsychopharmacology 15:541-554, 1996]
From the Center for Functional Imaging (TEN, NK, AMC, JE, RHH, WJ, TFB), Lawrence Berkeley National Laboratory, University of California, Berkeley; Department of Psychiatry (TEN, CC, AMC, LO'S-C, LR), University of California, Davis; Department of Neurology (LR, WJ), University of California, Davis; Center for Neuroscience (LR), University of California, Davis; Department of Pathology (SS), University of California, Davis.

Address correspondence to: Thomas E. Nordahl, Center for Functional Imaging, 55-121, Lawrence Berkeley National Laboratory, 1 Cyclotron Road, Berkeley, CA 94720.

Presented in part at the 1992 and 1993 American College of Neuropsychopharmacology and at the 1993 meeting of the American Psychiatry Association. This study was funded in large part by NIMH grant MH-46990.

SS is now in the Department of Surgical Pathology, Clinical Science Center, University of Wisconsin, Madison WI. CC is now with the Department of Psychiatry, University Pittsburgh Medical Center, Western Psychiatric Inst. and Clinic, Pittsburgh, PA.

Received December 11, 1995; accepted April 22, 1996.
KEY WORDS: Schizophrenia; Positron emission tomography (PET);[F-18]-2-fluoro-2-D-deoxyglucose (FDG); Temporal lobe; Repeated measures ANOVA

In this study we used high spatial resolution positron emission tomography (PET) and F-18-1abeled fluorodeoxyglucose (FDG) in order to study medial and lateral temporal cortical regions, basal ganglia, and anterior cingulate in unmedicated patients with chronic schizophrenia. Many lines of evidence, including magnetic resonance imaging (MRI), PET, electrophysiologic studies, and temporal lobe stimulation studies have implicated medial as well as lateral temporal lobe structures in the pathophysiology of schizophrenia symptoms (Barta et al. 1990; Buchsbaum et al. 1990, 1992; Catafau et al. 1994; Chua and McKenna 1995; DeLisi et 
al. 1989; Gur and Pearlson 1993, Lee et al. 1988; Shenton et al. 1992; Siegel et al. 1993; Tamminga et al. 1992). In previous work using a poorer resolution tomograph we found evidence of abnormal medial and lateral temporal metabolism but no evidence of striatal abnormalities in patients with schizophrenia (Cohen et al. 1987, 1989). Based upon our previous findings as well as findings in the literature we predicted that there would be medial temporal hypometabolism as well as lateral temporal cortical metabolic abnormalities, but no striatal metabolic abnormalities for our schizophrenia patients with active positive symptoms.

We imaged three slices parallel to the long axis to the temporal lobe and one to two superior slices through the basal ganglia and the thalamus with a high resolution (2.6 $\mathrm{mm}$ in plane and $6 \mathrm{~mm}$ axially) PET scanner. The high resolution of the scanner permitted us to sample and quantitate smaller regions of the brain than heretofore possible on commercially available PET systems. To better visualize the temporal lobe, we imaged the brain parallel to the long axis of the temporal lobe rather than obliquely to the long axis as is generally done. To reduce the variation due to patient clinical state (Andreasen and Carpenter Jr. 1993), we chose to study mild to moderately (positively) symptomatic, medication-free outpatients. Trial-by-trial Stroop was also performed by most patients within a day of the imaging study. As their Stroop performance was abnormal, we performed a preliminary linear regression analysis, examining the relationship between Stroop performance and the rCMRglc of the anterior cingulate, and certain temporal lobe regions of interest.

\section{SUBJECTS AND METHODS}

Eighteen medication-free patients, 10 undifferentiated and eight paranoid subtype, who met DSM-III-R (American Psychiatric Association 1987) criteria for chronic schizophrenia, were studied (see Table 1). All but two patients were interviewed using the Structured Clinical Interview for DSM-III-R (SCID-P) (Spitzer et al. 1989). SCID-P evaluations were done on the other two patients via chart reviews. All but two of the patients had overt hallucinations or delusions at time of PET study. All were physically healthy (physical exam, urine analysis, complete blood count, and chemistry 20 panel, chest x-ray, electrocardiogram), and all except one had been outpatients for at least 2 months before the onset of the protocol. One patient, who had required inpatient treatment before the PET study, had just been competitively employed and was stable at the time of the PET study. PET studies of six additional subjects were not included in the analysis because of positive toxicology screens for amphetamine (2) and opiates (1), recent unauthorized antipsychotic use (1), insufficient washout of haloperidol decanoate (1), or poor quality PET scans (1).

At the time of the PET study, all patients had been withdrawn from oral antipsychotics for a minimum of two weeks. Three subjects had their last decanoate injection approximately 12 weeks before the study and were placed on oral antipsychotic until 2 to 3 weeks before the study. Some subjects required anticholinergic medications or chloral hydrate during neuroleptic washout. However, anticholinergic medications and

Table 1. Patient Characteristics

\begin{tabular}{|c|c|c|c|c|c|c|c|}
\hline & $\begin{array}{c}\text { Patient } \\
\text { Age/sex/SSAS }\end{array}$ & $\begin{array}{l}\text { Duration of } \\
\text { Illness, } y\end{array}$ & $\begin{array}{l}\text { Drug-Free } \\
\text { Period, wks }\end{array}$ & $\begin{array}{l}\text { 1-18BPRS } \\
\text { Total }\end{array}$ & $\begin{array}{c}\text { BPRS }+ \\
\text { Total }\end{array}$ & $\begin{array}{l}\text { Negat } \\
\text { Symp }\end{array}$ & $\begin{array}{l}\text { Subtype } \\
\text { Diagnosis }\end{array}$ \\
\hline 1. & $26 / \mathrm{m} / 49$ & 15.0 & 300.0 & 47.0 & 16.0 & 49.0 & undifferentiated \\
\hline 2. & $28 / \mathrm{m} / 44$ & 9.0 & 2.4 & 57.0 & 16.0 & 48.0 & undifferentiated \\
\hline 3. & $\mathrm{~m} / 35 / 46$ & 15.0 & 2.4 & 66.0 & 16.0 & 32.0 & undifferentiated \\
\hline 4. & $\mathrm{~m} / 33 / 42$ & 13.0 & 2.9 & 38.0 & 14.0 & 69.0 & undifferentiated \\
\hline 5. & $\mathrm{~m} / 27 / 20$ & 13.0 & 3.0 & 58.0 & 18.0 & 61.0 & undifferentiated \\
\hline 6. & $\mathrm{~m} / 25 / 65$ & 10.0 & 2.6 & 51.0 & 16.0 & 58.0 & undifferentiated \\
\hline 7. & $\mathrm{~m} / 28 / 26$ & 5.0 & 75.0 & 38.0 & 12.0 & 24.0 & undifferentiated \\
\hline 8. & $\mathrm{~m} / 39 / 34$ & 21.0 & 3.0 & 36.0 & 12.0 & 61.0 & undifferentiated \\
\hline 9. & $\mathrm{~m} / 27 / 47$ & 8.0 & 300.0 & 44.0 & 11.0 & 31.0 & undifferentiated \\
\hline 10. & $\mathrm{~m} / 27 / 45$ & 6.0 & 2.3 & 42.0 & 11.0 & & undifferentiated \\
\hline 11. & $\mathrm{~m} / 20 / 65$ & 2.5 & 3.6 & 49.0 & 14.0 & & paranoid \\
\hline 12. & $\mathrm{~m} / 49 / 37$ & 9.0 & 2.0 & 50.0 & 10.0 & & paranoid \\
\hline 13. & $\mathrm{f} / 27 / 58$ & 5.0 & 2.4 & 59.0 & 14.0 & 46.0 & paranoid \\
\hline 14. & $\mathrm{~m} / 34 / 32$ & 10.0 & 3.0 & 58.0 & 20.0 & 34.0 & paranoid \\
\hline 15. & $\mathrm{~m} / 33 / 26$ & 10.0 & 2.3 & 40.0 & 14.0 & & paranoid \\
\hline 16. & $\mathrm{~m} / 43 / 52$ & 26.0 & 2.4 & 46.0 & 15.0 & 47.0 & paranoid \\
\hline 17. & $\mathrm{~m} / 32 / 35$ & 7.0 & 2.7 & 30.0 & 8.0 & 34.0 & paranoid \\
\hline \multirow[t]{2}{*}{18.} & $\mathrm{~m} / 33 / 33$ & 7.0 & 2.0 & 34.0 & 11.0 & 40.0 & paranoid \\
\hline & & $10.6 \pm 5.9$ & $2.6 \pm 0.4$ & $47.6 \pm 10.7$ & $13.9 \pm 3.2$ & $45.3 \pm 13.5$ & \\
\hline
\end{tabular}


chloral hydrate were not permitted in the 48 hours before the study. Subjects who had required short acting benzodiazepines, such as alprazolam, were gradually tapered off this medication and had none for at least 48 hours before the study. Diphenhydramine was permitted 12 hours before the study in one subject.

The 18 schizophrenic patients consisted of 17 men and 1 woman. The schizophrenic patients had a mean age \pm standard deviation of $31.4 \pm 7.0$. Eleven normal controls were also studied. These consisted of 10 men and 1 woman with a mean age of $32.9 \pm 12.7$ years. One of the 11 controls was left-handed, whereas two of the 18 patients were left-handed by history. Controls were also chosen to approximately match the patients in terms of parental education (Control parents $=14.4 \pm$ 3.0 , years; Patient parents $=15.4 \pm 2.7$ years, $\mathrm{t}[24]=0.8$, $p=0.43$ ).

The normal controls were obtained from advertisements in local newspapers. Normal controls were evaluated by history and a semi-structured interview. Potential normal controls were excluded if they had a history of a neurologic or systemic disorder. In addition, they were required to have a normal physical exam within 1 year of the study. Normal controls were also required to have no personal history of DSM-III-R Axis I disorder nor any first-degree family member with a history of Axis I disorder. Potential normal volunteers were excluded if they met DSM-III-R criteria for substance dependence or if they had a history of substance abuse in the past year.

For each subject, the Spielberger State Anxiety Scale (SSAS) (Spielberger et al. 1970) and radial pulse were obtained at the time of the PET study. For patients, the Brief Psychiatric Rating Scale (Overall and Gorham 1962, 1976) Negative Symptom Assessment (NSA) (Alphs et al. 1989), and trial-by-trial Stroop Color Naming Task were performed within a day of the PET study while they were still medication-withdrawn. The Stroop task was done in a different environment described in detail in Carter et al. (1992).

\section{PET Procedures}

PET imaging was performed on the PET-600, a singleslice tomograph with a $2.6-\mathrm{mm}$ full-width half-maximum in plane resolution and 6-mm axial resolution. The characteristics of this tomograph have been described elsewhere (Derenzo et al. 1988; Valk et al. 1990; Jagust et al. 1991). The PET procedure is similar to that described by Jagust et al. (1993).

Briefly, subjects were studied in a "resting" (baseline) condition with eyes open and ears unoccluded. During the uptake period, the subjects were sitting in a chair, facing a blue screen in a dimly lit room. Sound consisted primarily of background equipment and fan noise. Before the study, an arterial catheter was inserted into the left radial artery, connected to thin teflon tubing wrapped around a plastic scintillator and passed through a peristaltic pump. The plastic scintillator was connected to a photomultiplier tube. The photomultiplier tube was linked to a computer for time course determination of blood radioactivity (Jagust et al. 1991, 1993).

Several seconds after beginning blood withdrawal through this apparatus, approximately $10 \mathrm{mCi}$ of FDG were injected into a right antecubital vein. At $30 \mathrm{~min}-$ utes, continuous blood withdrawal was stopped, the patient voided, and was positioned in the PET scanner with the gantry of the scanner tilted at an angle -20 degrees to the orbitomeatal line. This positioning assured that the angle of the tomographic slice would be parallel to the long axis of the temporal lobes and also permit good visualization of the medial temporal lobes (Jagust et al. 1993). Discrete sampling of $10 \mathrm{ml}$ of blood was obtained at approximately 30 -minute intervals after positioning the subject in the tomograph.

After placement in the tomograph, three parallel and contiguous slices were obtained through the middle of the temporal lobe and then one to two slices passing through the thalamus and striatum each containing at least 10 minutes of data and approximately $1 \times 10^{6} \mathrm{co}^{-}$ incidence events. Prior to obtaining emission scan data, a 3-minute transmission scan was performed at each level to correct for photon attenuation and to assist in patient positioning as described elsewhere (Jagust et al. 1993). The initial slice chosen was generally 2.5 to $3 \mathrm{~cm}$ above the external auditory meatus (eam), depending upon the head size. In most subjects this produced a slice running through the midportion of the long axis of the temporal lobe, capturing medial temporal lobe. Before acquiring the initial emission scan, a transmission scan and a 5-minute "scout" emission scan were acquired and compared with a set of high resolution transmission scans and emission scans, respectively, on a standard subject (see Figure 1). This comparison could potentially lead to a repositioning of the scanner for the acquisition of the "hippocampal slice" emission scan (see Figures 1 and 2). MRI, when available, was also used to aid in the selection of the hippocampal slice. Two subsequent emission scans were obtained, one 2.5 $\mathrm{mm}$ above and one $2.5 \mathrm{~mm}$ below this slice in order to ensure medial temporal lobe tissue above and below the hippocampal slice. After acquisition of the temporal lobe slices one to two parallel slices 2.0 to $2.5 \mathrm{~cm}$ above the hippocampal slice were also obtained. This allowed us to obtain a "striatal slice" passing through the thalamus and striatum as well as the inferior portion of the anterior cingulate (see Figure 3). The striatal slice was $2.38 \pm 0.31 \mathrm{~cm}$ above the hippocampal slice for the normal controls and $2.43 \pm 0.36 \mathrm{~cm}$ above the hippocampal slice for the patients. Calibration of the arterial blood 

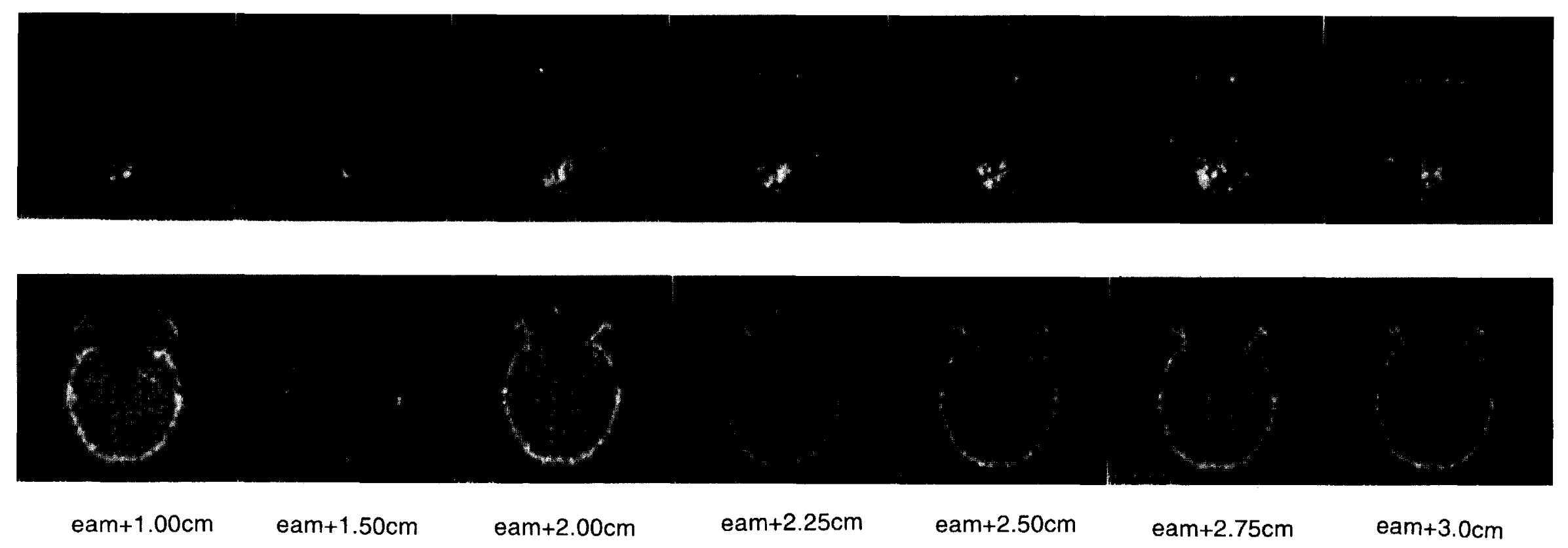

Figure 1. The series of high resolution emission and transmission images displayed represent a subset of the images obtained on our prototype subject and were used to aid in hippocampal slice selection. eam = external auditory meatus. 


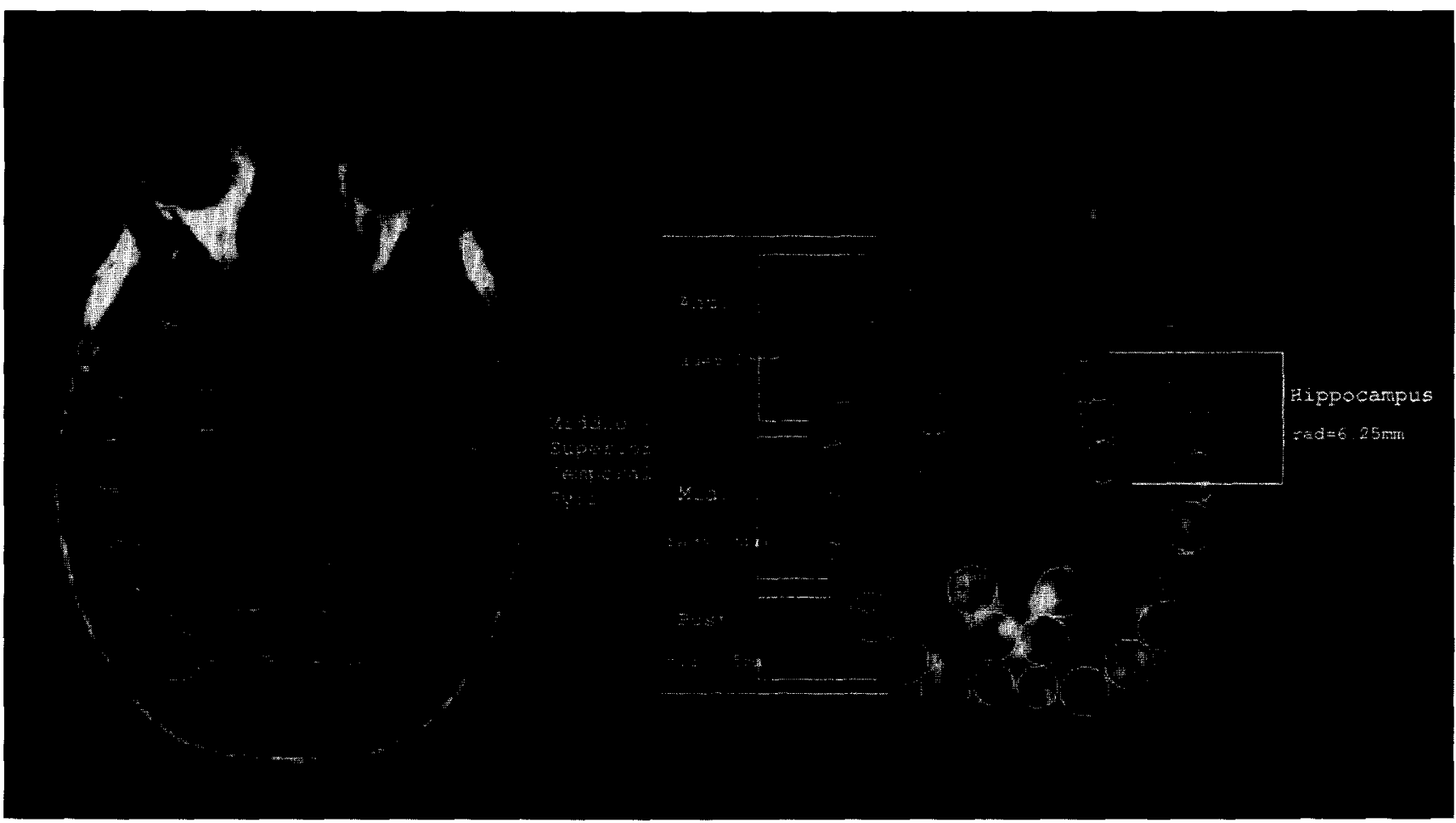

Figure 2. Circular ROIs are displayed on a hippocampal slice emission image (right). An MRI (left) is displayed, in a case in which we had MRI, showing the location of the circular ROIs on the corresponding structural image. rad= radius.

sampling apparatus and the PET scanner was performed at the end of the study using a radioactive standard.

\section{Stroop Procedure}

Our Stroop procedure, performed either the day before or after the PET procedure, involved a trial-by-trial presentation of words written with different colors (data reported in Carter et al. 1992, 1993). Words were considered congruent if they spelled out the same color as the color of the ink they were written in, incongruent if they spelled out a color different from the color of the ink, and neutral if they spelled an animal name rather than a color name. Subjects were instructed to name the color of the ink as quickly and correctly as possible while vocal reaction times and errors were measured. Facilitation (speeded color naming of congruent words over neutral words) was found to be abnormally high in patients with schizophrenia (Carter et al. 1992). Interference (speeded color naming neutral words over incongruent words) was found to be abnormally high only in a subgroup of patients with paranoid schizophrenia (Carter et al. 1993).

\section{Data Analysis}

Metabolic rates were calculated in cortical and subcortical regions of interest (ROIs) in the hippocampal and striatal slices. The hippocampal slice contained a total of 32 circular ROIs (Figure 2). The striatal slice contained a total of 38 circular ROIs (Figure 3). Placement of the circles on each slice was done blind to diagnosis (NK and JE) in a semi-automatic fashion (Jagust et al. 1993). Adjustments of individual circles were made to conform to the cortical surface and to minimize overlap between adjacent circular ROIs. Regional cerebral glucose metabolic rates (rCMRglcs) of the circular ROIs were obtained by using the arterial input function and the operational equation (Phelps et al. 1979; Reivich et al. 1985; Sokoloff et al. 1977), with rate constants $\mathrm{k}_{1}=$ $0.161, \mathrm{k}_{2}=0.168$, and $\mathrm{k}_{3}=0.098$, determined for normal controls using the PET-600 tomograph in an earlier study (Jagust et al. 1991) and the rate constant $\mathrm{k}_{4}=$ 0.0068 determined by Phelps et al. (1979).

For each tomograph slice, the circular ROIs were averaged (weighted by area) to evaluate rCMRglc in larger cortical or subcortical regions. The circular regions and their diameters are indicated in Figures 2 and 3. MRIs exist for some of the subjects and are included to show the localization on a structural image. Figure 4 shows the approximate position of the hippocampal slice on a rendered image of the lateral surface of a brain. Circle diameters were chosen to "cover" apparent cortical and subcortical gray matter on the PET image of the standard normal control. Labeling of the ROIs was accomplished with the help of a standard atlas (Matsui and Hirano 1978). In addition, we serially 


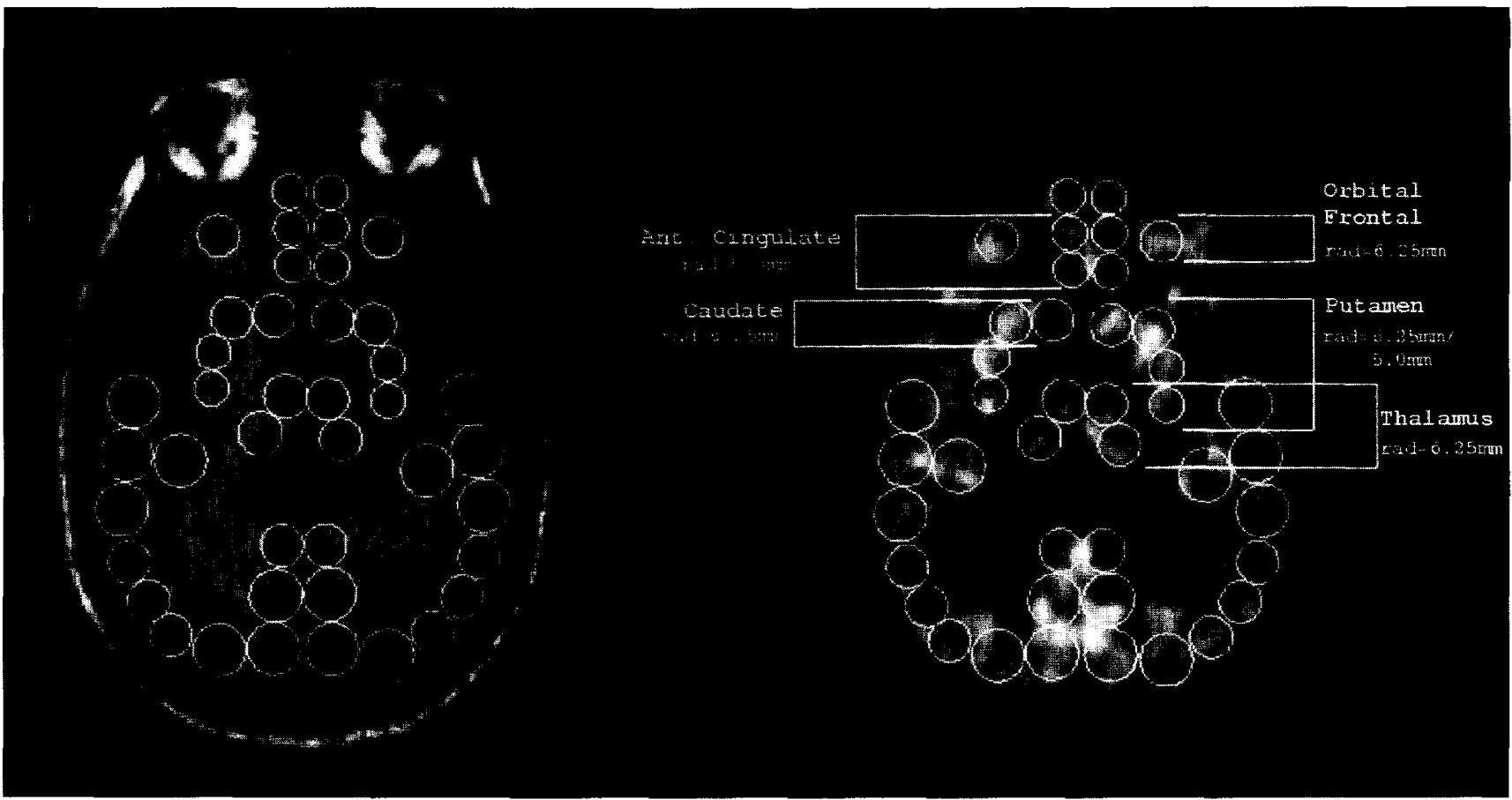

Figure 3. Circular ROIs are displayed upon a striatal slice emission image (right). The corresponding MRI image at this level (left) is also displayed.

sectioned three frozen heads into $7-\mathrm{mm}$ thick slices at the same -20 degree angle used in the PET study; medical and lateral surface markers were then used to further localize brain structures (Crosby et al. 1962). When MRI was available we checked this technique further; we chose the 20-degree hippocampal slice on a rendered MRI image of the full head and then projected this slice onto a rendered image of the brain. This confirmed what we had seen with cuts of frozen heads; namely that the 20-degree cut was parallel to the long axis of the temporal lobe and the "hippocampal slice" sampled medial temporal lobe (sampling hippocampus and amygdala as well as parahippocampal cortex). In the hippocampal slice, the ROIs were divided into three lateral temporal cortical regions: anterior, middle, and posterior (each sampling predominantly middle and superior temporal gyrus) and what we call the "hippocampus" (containing sampling primarily hippocampus and amygdala as well as parahippocampal cortex) bilaterally. No attempt was made to separate amygdala from hippocampus. In the striatal slice, the ROIs consisted of the (inferior) anterior cingulate (also containing sampling from the medial prefrontal cortex), and the caudate and putamen bilaterally.

\section{Metabolic and Clinical-Metabolic Comparisons}

Two-tailed Student $t$-test comparisons were made for the 18 patients and 11 controls comparing the whole slice glucose metabolic rates. Subsequently, regional metabolic rates normalized to whole slice CMRglc were compared. First, we compared normalized rCMRglc in the left and right hippocampus in patients and controls as we had expected to see abnormally low values in these ROIs. Next, the six temporal cortical ROIs were examined using a repeated measures ANOVA. There was one (independent) between measure consisting of diagnostic groups (normals, schizophrenics), and two within repeated measures: hemisphere (left, right), and position (anterior, middle, posterior) with the dependent measure being temporal lobe rCMRglc. This multivariate analysis was performed to evaluate laterality and anterior-posterior differences in temporal lobe metabolic rates in patients and controls. The rCMRglc of the anterior cingulate was tested using the Student $t$-test as it has significant dopamine innervation (Lewis et al. 1988), and it is activated by the Stroop cognitive task (Bench et al. 1993; Pardo et al. 1990; Carter et al. 1995). Finally, the four striatal ROIs (caudate and putamen bilaterally) were examined using a repeated measures ANOVA. There was one (independent) between measures consisting of diagnostic groups (normals, schizophrenics), and two (repeated) within measures: hemisphere (left, right) and striatum (caudate, putamen) with dependent measure being rCMRglc. Based upon our previous work we did not expect this to be abnormal though the striatum receives significant dopamine innervation (Waddington 1993). 


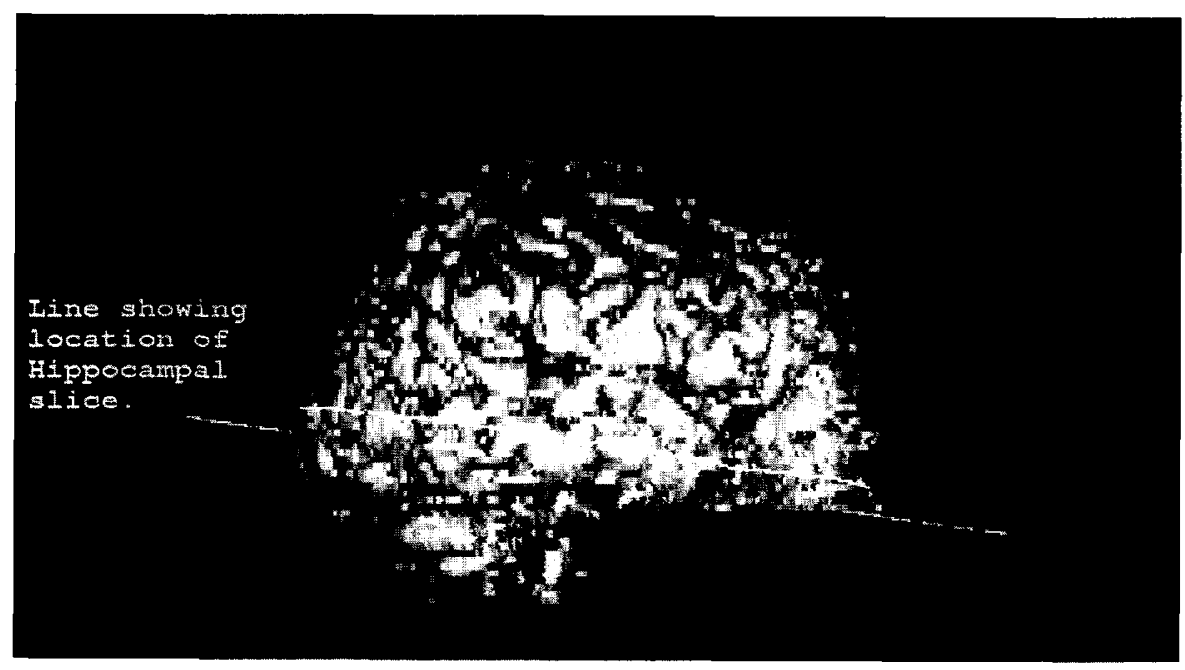

Figure 4. The rendered MRI brain image demonstrates the location of the hippocampal slice. This slice is roughly parallel to the long axis of the temporal lobe and lies in the middle and superior temporal gyri.

Linear regression analyses were performed for the group of patients comparing positive symptoms, obtained from the BPRS, with hippocampal and striatal slice average cortical gray metabolism. Regression analyses for the patient group were also performed, comparing certain clinical measures with the rCMRglc of the hippocampus and regions of interest (ROIs) tested which demonstrated metabolic abnormality. Clinical measures included Negative Symptom Assessment (NSA), BPRS, BPRS positive symptoms (BPRS+) (include items \#4: conceptual disorganization, \#11: suspiciousness, \#12: hallucinatory behavior, and \#15: unusual thought content from the BPRS), and Spielberger State Anxiety Scale. Linear regression analyses were also performed for patients, comparing Stroop facilitation and interference with rCMRglc of the anterior cingulate and the ROIs whose rCMRglc was abnormal.

\section{RESULTS}

\section{Clinical Differences (Table 2)}

Patients and normal controls did not differ from each other on age, sex, handedness, or parental education. Not unexpectantly, the patients had higher state anxiety (SSAS), positive symptoms (BPRS+), and pulse rates than controls.

\section{Metabolic Differences-Whole Slice Cortical Gray Matter}

The average cortical CMRglc in the hippocampal slice was not significantly different in patients and controls (normals: $9.41 \pm 1.47$, schizophrenics: $8.73 \pm 1.75$; $\mathrm{t}[26]=-1.07, p=.30$ ). The average cortical CMRglc in the striatal slice also exhibited no significant difference (normals: $10.0 \pm 1.22$, schizophrenics: $9.21 \pm 1.85$, $\mathrm{t}[22]=14, p=.27)$. The units for the metabolic rates are (mg glucose) $/(100 \mathrm{gm}$ tissue $) /(\mathrm{min})$.

Regional Metabolic Differences (Tables 3, 4, 5). Certain individual ROIs exhibited rCMRglc differences. As predicted, the left hippocampal rCMRglc was significantly lower in the patients than in the controls $(\mathrm{t}[27]=-2.37$, $p=.025$ ). The right hippocampal rCMRglc was not significantly lower in patients than in controls $(\mathrm{t}$ [27] $=$ $-1.62, p=.12$ ). The between-group main effect in the temporal lobe repeated measures ANOVA was not different in the patients than in the controls $(F[1]=0.27$, $p=.61$ ). Although the overall hemispheric comparison was significantly different $(F[1,27]=5.03, p=.03)$ there was no significant hemisphere by diagnostic group difference $(\mathrm{F}[1,27]=0.40, p=.53)$ and no three-way interaction $(\mathrm{F}[2,26]=1.73, p=.20)$. There was an overall significant finding related to relative position (anterior, middle, posterior) within the temporal cortex $(\mathrm{F}[2,26]=$ $29.43, p=.0001$ ) and more importantly a significant interaction between diagnosis and position $(\mathrm{F}[2,26]=$ $6.38, p=.006$ ). Follow-up univariate comparisons between patients and controls of the anterior, middle, and posterior temporal cortical regions (with left and right

Table 2. Clinical Data

\begin{tabular}{lclc}
\hline & $\begin{array}{c}\text { Normals } \\
(\boldsymbol{n}=\mathbf{1 1})\end{array}$ & $\begin{array}{c}\text { Patients } \\
(\boldsymbol{n}=\mathbf{1 8})\end{array}$ & $\boldsymbol{p}$ \\
\hline Age & $32.9 \pm 12.7$ & $31.4 \pm 7.0$ & 0.69 \\
Sex & $10 \mathrm{M} / 1 \mathrm{~F}$ & $17 \mathrm{M} / 1 \mathrm{~F}$ & 0.73 \\
Handedness & $10 \mathrm{R} / 1 \mathrm{~L}$ & $16 \mathrm{R} / 2 \mathrm{~L}$ & 0.87 \\
Parent & & & \\
$\quad$ education & $14.4 \pm 3.0 \mathrm{yrs}$ & $15.4 \pm 2.7 \mathrm{yrs}$ & 0.43 \\
BPRS+ & $4.2 \pm 0.6$ & $13.8 \pm 3.0$ & 0.0001 \\
SSAS & $31.4 \pm 7.6$ & $41.6 \pm 12.8$ & 0.02 \\
PULSE & $61.7 \pm 11.0$ & $74.5 \pm 12.5$ & 0.02 \\
\hline
\end{tabular}


Table 3. Anterior Cingulate and Hippocampal Regions

\begin{tabular}{llllll}
\hline \multicolumn{1}{c}{ ROI } & NC $(\boldsymbol{n}=\mathbf{1 1})$ & SCH $(\boldsymbol{n}=\mathbf{1 8})$ & $d \mathbf{f}$ & $t$ & $p$ \\
\hline Hippocampus & & & & & \\
Left & $0.826 \pm 0.031$ & $0.774 \pm 0.069$ & 27 & 2.37 & $0.025^{a}$ \\
Right & $0.840 \pm 0.058$ & $0.787 \pm 0.098$ & 27 & 1.62 & 0.12 \\
Anterior cing. & $0.970 \pm 0.152$ & $1.035 \pm 0.113$ & 23 & 1.23 & 0.23 \\
\hline
\end{tabular}

The comparisons consist of two-tailed, $t$-tests.

$a_{p}$ values significant at the .05 level.

hemisphere values collapsed) demonstrated a significantly lower posterior temporal cortical metabolism in the patients than in the controls $(\mathrm{t}[27]=-3.62, p=$ .001). No anterior cingulate rCMRglc abnormality was noted. The repeated measures ANOVA of striatal metabolism showed no overall abnormality and no significant interaction of interest.

\section{Metabolism Versus Clinical Symptom and Stroop Performance (Tables 6, 7)}

The BPRS+ negatively correlated with the average striatal slice CMRglc $(d f=13, r=-0.60, p=.02)$. The anterior cingulate rCMRglc was highly positively correlated with Stroop facilitation ( $d f=12, r=+0.70, p=.005$ ). The left hippocampal rCMRglc showed a moderate, yet nonsignificant, negative correlation with Stroop interference $(d f=13, r=-0.37, p=.20)$.

\section{Exploratory Analysis}

Because of our special interest in the hippocampus we examined further for evidence of a potential relationship between left hippocampal metabolism and Stroop performance. We performed a one-way ANOVA comparing left hippocampal rCMRglc in controls, patients with high Stroop interference, and in patients with lower Stroop interference based upon median split

Table 4. Lateral Temporal Cortical ROIs Analyzed by Repeated Measures ANOVA

\begin{tabular}{lll}
\hline Temporal cortex & NC $(\boldsymbol{n}=\mathbf{1 1})$ & SCH $(\boldsymbol{n}=\mathbf{1 8})$ \\
\hline Left anterior & $0.876 \pm .076$ & $0.894 \pm .059$ \\
Right anterior & $0.880 \pm .087$ & $0.926 \pm .086$ \\
Left middle & $0.963 \pm .107$ & $1.017 \pm .060$ \\
Right middle & $1.003 \pm .045$ & $1.008 \pm .083$ \\
Left posterior & $1.023 \pm .069$ & $0.947 \pm .085^{a}$ \\
Right posterior & $1.056 \pm .072$ & $0.967 \pm .076^{a}$ \\
\hline
\end{tabular}

(Diagnosis: $\mathrm{F}[1]=0.27, p=.61)$, (Hemisphere: $\left.\mathrm{F}[1,27]=5.03, p=.03^{a}\right)$ (Hemis ${ }^{*}$ Diag: $\mathrm{F}[1,27]=0.40, p=.53$ ), (Position: F[2,26] $=29.43, p=$ $\left..0001^{a}\right)$, (Position*Diag: F[2,26] $=6.38, p=0.006^{a}$ ) Group is the sole between comparison, Hemisphere (left, right) and Position (anterior, middle, posterior) are the two within subject measures.

${ }^{a} p$ values significant at the .05 level. technique. The overall ANOVA showed a significant difference (high interf pts. $=0.729$, low interf pts. $=$ 0.800 , controls $=0.826 ; \mathrm{F}[2]=7.34, p=.0036)$. Followup univariate comparison showed a significant difference between the patients with high interference and normal controls $(\mathrm{t}[16]=3.88, p=.001)$ and a trend toward a difference between patients with high and low Stroop interference $(\mathrm{t}[12]=2.03, p=.065)$.

We remark that all hippocampal findings in this study are virtually identical whether we use all three circular ROIs or only the two more anterior circular ROIs to estimate hippocampal region rCMRglc (see Figure 2).

\section{DISCUSSION}

This is the first study of temporal lobe regional metabolic rates in schizophrenia imaging the temporal lobe parallel to its long axis with a PET tomograph having an in-plane resolution of $2.6 \mathrm{~mm}$. Consistent with the findings of other investigators, significant differences were not seen for whole slice cortical CMRglc. However, normalized medial and lateral temporal regional metabolic differences were noted. In particular, the left hippocampal and posterior temporal cortical rCMRglc were lower in patients with schizophrenia than in the normal controls. Consistent with our expectation, there were no striatal metabolic abnormalities. Whereas the average striatal slice cortical gray metabolism significantly correlated with positive symptoms in patients,

Table 5. Striatal ROIs Analyzed by Repeated Measures ANOVA

\begin{tabular}{lcc}
\hline \multicolumn{1}{c}{ ROI } & NC (9) & SCH (16) \\
\hline Left caudate & $1.128 \pm .138$ & $1.034 \pm .113$ \\
Right caudate & $1.035 \pm .190$ & $0.992 \pm .191$ \\
Left putamen & $1.167 \pm .090$ & $1.206 \pm .109$ \\
Right putamen & $1.189 \pm .138$ & $1.210 \pm .095$ \\
\hline
\end{tabular}

(Diagnosis: $\mathrm{F}[1]=0.21, p=.65$ ), (Hemisphere: $\mathrm{F}[1,23]=1.80, p=.19$ ) (Hemis*Diag: $\mathbf{F}[1,23]=.17, p=.69$ ), (Striatum*Diag: $\mathrm{F}[23]=3.59, p=$ .07) Group is the sole between measure, Hemisphere (Left, Right) and Striatum (Caudate, Putamen) are the two within subject measures. 
Table 6. Cognitive-Metabolic Correlation

\begin{tabular}{|c|c|c|c|c|c|c|}
\hline & \multicolumn{3}{|c|}{$\begin{array}{c}\text { Interference } \\
\quad(n=14)\end{array}$} & \multicolumn{3}{|c|}{$\begin{array}{c}\text { Facilitation } \\
\quad(n=14)\end{array}$} \\
\hline & $\mathbf{R}$ & $\mathbf{F}$ & $p$ & $\mathbf{R}$ & $F$ & $p$ \\
\hline Hippocampal slice & +0.16 & 0.28 & 0.61 & -0.17 & 0.33 & 0.57 \\
\hline Striatal slice & +0.09 & 0.09 & 0.77 & +0.21 & 0.52 & 0.48 \\
\hline Anterior cingulate & +0.38 & 2.06 & 0.18 & +0.70 & 11.65 & $0.005^{a}$ \\
\hline L hippocampus & -0.37 & 1.88 & 0.20 & +.11 & 0.15 & 0.71 \\
\hline Posterior temporal & -0.24 & 0.74 & 0.41 & -.12 & 0.17 & 0.69 \\
\hline
\end{tabular}

Clinical-metabolic correlations in the patients with schizophrenia. The letter $\mathrm{R}$ represents the Pearson correlational coefficient and $p$ represents the two-tailed $p$-value.

${ }^{a}$ Correlations with significance at .05 level of confidence or better.

no significant correlation was noted between either positive or negative symptoms and either hippocampal or posterior temporal cortical rCMRglc. No anterior cingulate rCMRglc abnormality was noted for the patients; however, the Stroop facilitation was highly positively correlated with the anterior cingulate rCMRglc for the patients.

Several PET or SPECT studies have found similar posterior temporal metabolic findings. Cleghorn et al. (1992), using PET-FDG, imaged unmedicated patients with schizophrenia at a -5 degree angle to the orbitalmetal line and reported similar posterior temporal findings. Specifically, these authors reported bilaterally decreased posterior superior temporal metabolism in 12 patients who were hallucinating during uptake of tracer compared with 10 patients who were not hallucinating. Their posterior temporal regions were chosen in order to sample auditory cortex and Wernicke's region. Because their PET method included a slice thickness of 12 to $15 \mathrm{~mm}$, their sampling likely overlapped with our posterior temporal cortical sampling, imaging primarily within the middle and superior temporal gyri. These investigators point out that similar blood flow decreases in Wernicke's region were also seen in an ox-

Table 7. Clinical-Metabolic Correlation

\begin{tabular}{|c|c|c|c|c|c|c|}
\hline & \multicolumn{3}{|c|}{$\begin{array}{c}\text { Negative } \\
\text { Symptom Assess. } \\
(n=14)\end{array}$} & \multicolumn{2}{|c|}{$\begin{array}{c}\text { BPRS }+ \\
(n=17)\end{array}$} & \multirow[b]{2}{*}{$p$ Slice } \\
\hline & $\mathbf{R}$ & $\mathbf{F}$ & $p$ & $\mathbf{R}$ & $\mathbf{F}$ & \\
\hline Hippo slice & -0.47 & 3.14 & 0.10 & -.33 & 1.81 & 0.19 \\
\hline Striatal slice & -0.50 & 3.73 & 0.08 & -.60 & 7.48 & $0.02^{a}$ \\
\hline \multicolumn{7}{|l|}{ Regional } \\
\hline L hippocampus & -0.10 & 0.13 & 0.73 & -.04 & .02 & 0.88 \\
\hline Posterior temporal & -0.22 & 0.60 & 0.45 & +.18 & 0.54 & 0.47 \\
\hline
\end{tabular}

Clinical-metabolic correlations in the patients with schizophrenia. The letter $\mathrm{R}$ represents the Pearson correlational coefficient and $p$ represents the two-tailed $p$-value.

${ }^{a}$ Correlations with significance at .05 level of confidence or better. ygen-15 blood flow study of subjects required to read words aloud (Frith et al. 1991). Other PET studies (Demonet et al. 1992; Howard et al. 1992) have noted that the left temporal contribution to language function was not restricted to Wernicke's area but extends to the middle temporal gyrus. We did not specifically ascertain if patients were hallucinating during uptake, but all but two of our patients had overt hallucinations or delusions within a day of the study when the BPRS was performed. Other functional imaging studies have linked the presence of positive symptoms with decreased posterior temporal cortical function. Liddle et al. (1992) found an inverse correlation between what they termed "reality distortion," a factor largely determined by presence of delusions and auditory hallucinations, and right posterior superior temporal cortical blood flow in stable, medicated patients. Gur et al. (1995) found for unmedicated patients with schizophrenia, using the PETFDG technique, an inverse correlation between superior temporal lobe metabolism and global hallucinations. Catafau et al. (1994) found, using SPECT, significantly lower left posterior temporal cortical blood flow in neuroleptic-naive female patients with acute schizophrenia than in controls. Related findings were found by Starkstein et al. (1994) in a SPECT study of delusional Alzheimer's disease patients compared with a matched group of nondelusional Alzheimer's disease patients.

Some temporal lobe MRI volume findings in schizophrenia are of special interest. Shenton et al. (1992) found an inverse relationship between an index of thought disorder and the MRI volume of the left posterior superior temporal gyrus and Barta et al. (1990) found an inverse relationship between auditory hallucinations and the MRI volume of the left superior temporal gyrus. Findings such as these might lead us to predict that our patients, who have prominent positive symptoms, might have less left superior temporal cortical gray matter than the normal controls. This could lead to artificially lower temporal lobe metabolic estimates, via PET, in patients due to partial voluming effects and consequently lead to false differences between the groups (Type I error) or no apparent differences in cases where the true metabolic rate in the patients was actually higher than that of the controls (Type II error). The normalization quotient (regional metabolism/ whole slice metabolism) might give some protection against partial volume errors. This may follow, for example, from work of Zipursky et al. $(1992,1994)$ who found, in addition to bilateral decreases in superior temporal cortical gray matter, generalized cortical decreases in gray matter of schizophrenics. On the other hand, PET studies with tomographs with axial thickness significantly greater than the $6 \mathrm{~mm}$ of the PET- 600 could miss posterior superior temporal cortical metabolic abnormalities. This follows as their posterior superior temporal sampling might include sampling from 
other nearby structures such as parietal cortex in which rCMRglc has been reported to be elevated in patients with schizophrenia compared with normal controls (Mathew et al. 1988).

This study involved a special effort to sample medial temporal cortical tissue, including obtaining multiple images through the medial temporal cortex at an angle parallel to the long axis of the temporal lobe to ensure full thickness of the tissue being sampled. As predicted, we found evidence of significantly lower left hippocampal rCMRglc in the patients than in controls. Most investigators (Buchsbaum et al. 1992; Siegel et al. 1993; Tamminga et al. 1992; Cohen et al. 1989) although not all (Musalek et al. 1989) have found lower hippocampal rCMRglc in patients with schizophrenia than in normal controls. Several studies, of unmedicated schizophrenics with positive symptoms, have found abnormally decreased anterior cingulate rCMRglc concomitantly with hippocampal hypometabolism (Buchsbaum et al. 1992; Siegel et al. 1993; Tamminga et al. 1992). We did not find abnormal anterior cingulate rCMRglc, and this might be because we were sampling only the inferior portion of the anterior cingulate.

The hippocampus and amygdala are small structures and so are susceptible to significant partial voluming errors (see recovery coefficients, p. 497, Phelps et al. 1986). If there were significant gray matter loss in the hippocampus of the patients, this might lead to additional partial voluming errors and lower estimates of patient metabolic rates. Many (Bogerts et al. 1990, 1993; Breier et al. 1992; DeLisi et al. 1988; Suddath et al. 1989, 1990; Shenton et al. 1992; Marsh et al. 1994; Rossi et al. 1994), but again certainly not all MRI studies (Colombo et al. 1993; Dauphinais et al. 1990; Kawasaki et al. 1993; Kelsoe et al. 1988; Young et al. 1991) have found significantly decreased (left) hippocampal/amygdala volume in patients with schizophrenia. If the patients had decreased hippocampal volume, then the measured rCMRglc values in these patients could be artificially lower than the true metabolic rate due to partial volume errors. This is an important issue that needs to be investigated further.

The hippocampus and other medial temporal structures are important brain regions involved in memory and cognition (Squire 1987). It has been shown that electrical stimulation of the hippocampus in humans could lead to intrusive memories at certain voltages, and at higher voltages the current reality could be blocked out (Chapman et al. 1967; Lee et al. 1988; Chapman personal communication). Our preliminary analysis using median split technique, breaking patients into high and low Stroop interference, suggests that the hippocampal metabolic differences in these patients was most prominent in patients who had abnormal Stroop interference. This needs to be explored further. Also, although we did not find a correlation for the patients be- tween positive symptoms and hippocampal metabolism seen in some studies (e.g., Friston et al. 1992; Liddle et al. 1992), this does not rule out such a relationship as the correlation procedure lacks power.

The anterior cingulate has been proposed as one component of an anterior attentional system (see, e.g., Petersen 1993). Consistent with this, as noted earlier, several studies have reported Stroop-induced activation of the anterior cingulate in normals. Devinsky et al. (1995) refer to the anterior cingulate as the "anterior executive region," which they break into "cognitive" (generally more superior) and "affective" (generally more inferior) components. Both components appear to be involved in selective attention as Carter et al. (1995) found trial-by-trial Stroop-induced superior as well as inferior anterior cingulate $\mathrm{rCBF}$ activation in normal controls. We found Stroop facilitation to be abnormally high in patients with schizophrenia (Carter et al. 1992, 1993) and in the present study facilitation (in patients), calculated from a Stroop task performed within a day of the PET study, correlated with resting inferior anterior cingulate rCMRglc. Performance of the Stroop task during the uptake of the tracer would have given a more controlled and taxing state than the resting (baseline) condition used in this study and possibly strengthened differences between the groups. However, the findings in this study suggest that even the resting metabolic pattern contains information regarding the level of performance on a cognitive task performed within a day.

A number of PET and SPECT studies of schizophrenia have noted an abnormally increased left or abnormally increased left relative to right temporal (whole brain in some studies) metabolism or blood flow in patients compared with controls (Buchsbaum et al. 1992; DeLisi et al. 1989; Gur et al. 1989; Sheppard et al. 1983; Siegel et al. 1993; Wilson et al. 1993). However not all studies have found this abnormal asymmetry (Wolkin et al. 1985; Jernigan et al. 1985; Cohen et al. 1987; Kishimoto et al. 1987). We did not see any evidence of a hemisphere by diagnosis interaction for either the temporal cortical or striatal ROI multivariate analyses. Many of the above schizophrenia studies that found evidence of abnormally increased left or increased left relative to right blood flow or metabolism involved patients who were neuroleptic naive and/or else more acutely symptomatic, and who often required hospitalization. Those studies above that did not find evidence of an abnormal metabolic asymmetry typically involved chronic, nonacutely symptomatic patients who had a history of treatment with neuroleptic medication. Our patients were primarily chronic outpatients with a history of neuroleptic treatment and although they had positive symptoms, they were not acutely symptomatic.

Of further interest, Buchsbaum et al. (1992) note that they found the greatest degree of metabolic asymmetry differences in the middle and inferior temporal gyrus. 
Sampling parallel to the long axis of the temporal lobe within the middle and superior temporal gyri we found that relative temporal lobe position (anterior, middle, posterior) was an important determinant in metabolic differences. Hence, relative position within a gyrus may also be important factor when analyzing asymmetry differences. Related to this, a major temporal lobe neuronal pathway flows parallel to the long axis of the temporal cortex from the posterior to more anterior regions (see, e.g., Ungerleider and Haxby 1994).

Like all published PET studies of schizophrenia to date, this study used fixed volume sampling and could not take full advantage of the resolution of the PET tomograph that might have been possible with MRIdelineated ROIs. In addition, MR segmentation of PET voxels into percent of gray matter, white matter, and CSF with subsequent use of rate constants for gray and white matter in metabolic calculations could lead to improved estimates of glucose metabolism. Consistent with the fact that we used a higher resolution tomograph with consequently less partial voluming errors, the absolute glucose metabolic rates obtained with the PET-600 are at least twice that of Buchsbaum et al. (1992) and Gur et al. (1995).

Next we discuss some of the possible type I and II errors not mentioned earlier. Two of the 11 controls and two of the 18 patients did not have a suitable striatal slice, so the comparison size is nine controls versus 16 patients for striatal slice ROIs. Although we correctly predicted that there would be no striatal metabolic abnormality, the decreased sample size for the striatal comparison may have played a role in the lack of a striatal finding. The literature concerning striatal metabolism is mixed. Buchsbaum et al. (1992) note that of 12 studies of unmedicated patients reporting normalized striatal data that six have reported low striatal values, five have reported high striatal values (three significant), and there was one "tie." More recent studies of unmedicated patients with schizophrenia by Tamminga et al. (1992) and Gur et al. (1995) did not find striatal metabolic abnormalities. Although we ran a number of statistical tests, we protected against type I error by performing follow-up testing only when the multivariate analysis was significant. Moreover, the hippocampal metabolic abnormality was predicted a priori. Although we expected lateral temporal cortical abnormalities, we did not have a specific prediction as to whether abnormalities would be more anterior or posterior or would be primarily left- or right-sided. Thus, posterior temporal cortical hypometabolism could represent type I error. However, if a Bonferroni-Dunn correction were performed this finding would still be significant and more importantly, as noted earlier, it is consistent with recent imaging findings in the literature. The nonsignificant 0.37 negative correlation between left hippocampal rCMRglc and Stroop interfer- ence might represent type II error due to the small (14) sample of patients involved in this correlational analysis. This is suggested by the positive findings of the ANOVA comparing left hippocampal rCMRglc among controls, patients with low Stroop interference, and patients with high Stroop interference. If the trial-by-trial Stroop task had been performed during the uptake, then there may have been clearer relationships between Stroop performance and regional metabolic rates.

Another issue to be considered involves the length of neuroleptic withdrawal. Is 2 to 3 weeks of neuroleptic withdrawal sufficient? Clow et al. (1980) note that 2 weeks after neuroleptic discontinuation, the dissociation constant for spiperone binding reverts to normal; however some behavioral effects such as enhanced stereotyped response disappear after only a month, and other neuroleptic associated effects take longer to disappear. Also, three of our patients were studied 12 weeks after their last injection of haldol decanoate. The data comparisons, however, remain essentially the same whether these patients are included or not. The Cleghorn et al. (1992) and Catafau et al. (1994) studies showing posterior temporal rCMRglc decreases involved primarily neuroleptic-naive patients, suggesting that the 2 to 3-week neuroleptic withdrawal was not a factor in our posterior temporal findings. Conversely, some studies have found temporal lobe metabolic increases associated with chronic neuroleptic treatment (see Cohen et al. 1996).

\section{CONCLUSIONS}

The strengths of this study include a high-resolution, improved visualization of the temporal lobe using images parallel to the long axis of the temporal lobe, and a group of neuroleptic-withdrawn outpatients who were limited to those patients with mild to moderately severe positive symptoms. Other PET and SPECT studies have found evidence of hippocampal and posterior temporal cortical hypofunction in patients compared with controls, especially in patients with overt positive symptoms. This study localizes temporal cortical hypometabolism to the posterior portion of the middle and superior temporal gyri. These medial and lateral temporal lobe regions play a role in memory or in processing auditory information and so may also play a role in positive psychotic symptoms. There are also several studies suggesting that those patients with increased positive symptoms may have decreased posterior temporal cortical volume, which in turn might lead to artificially lower PET estimates of regional glucose metabolism. Decreased tissue volume could also play a role in the finding of decreased hippocampal rCMRglc. We plan to follow this study with three-dimensional PET and MRI study taking MRI volume into account. 


\section{ACKNOWLEDGMENTS}

We thank Chawki Benkelfat, M.D., Robert Cohen, M.D., Ph.D., Louis Kraft, M.D., William Kremen, Ph.D. and Dolf Pfefferbaum, M.D. for their helpful suggestions. We also thank Mr. Ricky Tang and Ms. Mandy Young for their help in data analysis. This work was supported in part by NIMH Grant MH46990. This work was also supported in part by the Director, Office of Energy Research, Office of Health and Environmental Research, Medical Applications and Biophysical Research Division of the US Department of Energy under contract No. DE-AC03-76SF00098.

\section{REFERENCES}

Alphs LD, Summerfelt BS, Lann H, Muller RJ (1989): The negative symptom assessment: A new instrument to assess negative symptoms of schizophrenia. Psychopharmacol Bull 25:159-184

American Psychiatric Association (1987): Diagnostic and Statistical Manual Mental Disorders, 3rd ed. rev. Washington, DC, American Psychiatric Press

Andreasen NC, Carpenter WT, Jr (1993): Diagnosis and classification of schizophrenia. Schizoph Bull 19:199-214

Barta PE, Pearlson GD, Powers RE, Richards SS, Tune LE (1990): Auditory hallucinations and smaller superior temporal gyral volume in schizophrenia. Am J Psychiatry 147:1457-1462

Bench CJ, Frith CD, Grasby PM, Friston KJ, Paulesu E, Frackowiak RSJ, Dolan RJ (1993): Investigations of the functional anatomy of attention using the Stroop test. Neuropsychologia 31:907-922

Bogerts B, Ashtari M, Degreef G, Alvir JM, Bilder RM, Lieberman JA (1990): Reduced temporal limbic structural volumes on magnetic resonance images in first episode schizophrenia. Psychiatry Res: Neuroimaging 35:1-13

Bogerts B, Lieberman JA, Ashtari M, Bilder RM, Degreef G, Lerner G, Johns C, Masiar S (1993): Hippocampusamygdala volumes and psychopathology in chronic schizophrenia. Biol Psychiatry 33:236-246

Breier A, Buchanan RW, Elkashef A, Munson RC, Kirkpatrick B, Gellad F (1992): Brain morphology and schizophrenia: A magnetic resonance imaging study of limbic, prefrontal cortex, and caudate structures. Arch Gen Psychiatry 49:921-926

Brown R, Colter N, Corsellis JA, Crow TJ, Frith CD, Jagoe R, Johnstone EC, March L (1986): Postmortem evidence of structural brain changes in schizophrenia: Differences in brain weight, temporal horn area and parahippocampal gyrus compared with affective disorder. Arch Gen Psychiatry 43:36-42

Buchsbaum MS (1990): The frontal lobes, basal ganglia, and temporal lobes as sites for schizophrenia. Schizoph Bull 16:379-389

Buchsbaum MS, Haier RJ, Potkin SG, Nuechterlein K, Bracha HS, Katz M, Lohr J, Wu J, Lottenberg S, Jerabek PA, Trenary M, Tafalla R, Reynolds C, Bunney WE (1992): Frontostriatal disorder of cerebral metabolism in nevermedicated schizophrenics. Arch Gen Psychiatry 49:935942
Carter CS, Robertson LC, Nordahl TE (1992): Abnormal processing of irrelevant information in schizophrenia: Selective enhancement of Stroop facilitation. Psychiatry Res 41:137-146

Carter CS, Robertson LC, Nordahl TE, O'Shora-Celaya LJ, Chaderjian MC (1993): Abnormal processing of irrelevant information in schizophrenia: The role of illness subtype. Psychiatry Res 48:17-26

Carter CS, Mintun M, Cohen JD (1995): Interference and facilitation effects during selective attention: An ${ }^{15} \mathrm{O}$ $\mathrm{H}_{2} \mathrm{O}$ PET study of Stroop task performance. NeurImage 2:264-272

Catafau AM, Parellada E, Lomena FJ, Bernado M, Pavia J, Ros D, Setoain J, Gonzalez-Monclus E (1994): Prefrontal and temporal blood flow in schizophrenia: Resting and activation Technetium-99m-HMPAO SPECT patterns in young neuroleptic-naive patients with acute disease. J Nucl Medicine 35:935-941

Chapman LG, Walter RD, Markham CH, Rand RW, and Crandall PH (1967): Memory changes induced by stimulation of the hippocampus or amygdala in epilepsy patients with implanted electrodes, Trans Am Neurol Assoc 92:50-56

Chua SE, McKenna PJ (1995): Schizophrenia-A brain disease? A critical review of structural and functional cerebral abnormality in the disorder. Br J Psychiatry 166: 563-582

Cleghorn JM, Franco S, Szechtman B, Kaplan R, Szechtman H, Brown GM, Nahamias C, Garnett ES (1992): Toward a brain map of auditory hallucinations. Am J Psychiatry 149:1062-1069

Clow A, Theodorou A, Jenner P, Marsden CD (1980): Cerebral dopamine function in rats following withdrawal from one year of continuous neuroleptic administration. Eur J Pharmacol 63:145-157

Cohen RM, Semple WE, Gross M, Nordahl TE, King AC, Pickar D, Post RM (1989): Evidence for common alterations in cerebral glucose metabolism in major affective disorders and schizophrenia. Neuropsychopharmacology 2:241-254

Cohen RM, Semple WE, Gross M, Nordahl TE, DeLisi LE, Holcomb HH, King AC, Moihisa JM, Pickar D (1987): Dysfunction in a prefrontal substrate of sustained attention in schizophrenia. Life Sci 40:2031-2039

Cohen RM, Nordahl TE, Semple WE, Andreason P, Litman RE, Pickar MD (1996): The brain metabolic patterns of clozapine- and fluphenazine-treated schizophrenic patients. Arch Gen Psychiatry, in press

Colombo C, Amruzzese M, Livian S, Scotti G, Locatelli M, Bonfanti A, Scarone S (1993): Memory functions and temporal-limbic morphology in schizophrenia. Psychiatry Res: Neuroimaging 50:45-56

Crosby EC, Humphrey T, Lauer EW (1962): Correlative Anatomy of the Nervous System. MacMillan Company, New York

Dauphinais IK, DeLisi LE, Crow TJ, Alexandropoulos K, Colter N, Tuma I, Gershon ES (1990): Reduction in temporal lobe size in siblings with schizophrenia: A magnetic resonance imaging study. Psychiatry Res: Neuroimaging 35:137-147 
DeLisi LE, Dauphinais D, Gershon ES (1988): Perinatal complications and reduced size of brain structures in familial schizophrenia. Schizophr Bull 14:185-191

DeLisi LE, Buchsbaum MS, Holcomb HH, Langston $\mathrm{KC}$, King AC, Kessler R, Pickar D, Carpenter, Jr WT, Morihisa JM, Margolin R, Weinberger DR (1989): Increased temporal lobe glucose in chronic schizophrenic patients. Biol Psychiatry 25:835-851

Demonet JF, Chollet F, Ramsay S, Cardebat F, Nespoulous JC, Wise R, Rascol A, Frackowiak R (1992): The anatomy of phonological and semantic processing in normal subjects. Brain 115:1753-1768

Derenzo SE, Huesman RH, Cahoon JL, Geyer AB, Moses WW, Uber DC, Vuletich T, Budinger TF (1988): A positron tomograph with $600 \mathrm{BGO}$ crystals and $2.6 \mathrm{~mm}$ resolution. IEEE Trans Nucl Sci 35:659-664

Devinsky O, Morrell MJ, Vogt BA (1995): Contributions of anterior cingulate cortex to behavior. Brain 118:279-306

Frith CD, Friston K, Liddle PF, Frackowiak RS (1991): Willed action and the prefrontal cortex in man: A study with PET. Proc R Scod Lond (Biol) 244:241-246

Friston KJ, Liddle PF, Frith CD, Hirsch SR, Frackowiak RSJ (1992): The left medial temporal regions and schizophrenia. Brain 115:367-382

Gur RE, Resnick SM, Gur RC (1989): Laterality and frontality of cerebral blood flow and metabolism in schizophrenia: Relationship to symptom specificity. Psychiatry Res 27: 325-334

Gur RE, Pearlson GD (1993): Neuroimaging in schizophrenia research. Schizophr Bull 19:337-352

Gur RE, Mozley PD, Resnick SM, Mozley LH, Shtasel DL, Gallacher F, Arnold SE, Karp JS, Alavi A, Reivich M, Gur RC (1995): Resting cerebra glucose metabolism in first-episode and previously treated patients with schizophrenia relates to clinical features. Arch Gen Psychiatry $52: 657-667$

Howard D, Patterson K, Wise R, Brown D, Friston K, Weiller C, Frackowiak R (1992): The cortical localization of the lexicons. Brain 115:1769-1782

Jagust WJ, Seab JP, Huesman RH, Valk PE, Mathis CA, Reed BR, Coxson PG, Budinger TF (1991): Diminished glucose transport in Alzheimer's disease: Dynamic PET studies. J Cereb Blood Flow Metab 11:323-330

Jagust WJ, Eberling JL, Richardson BR, Reed BR, Baker MG, Nordahl TE, Budinger TF (1993): The cortical topography of temporal lobe hypometabolism in early Alzheimer's disease. Brain Res 629:189-198

Jernigan TL, Sargent T III, Pfefferbaum A, Kusubov N, Stahl SM (1985): Fluorodeoxyglucose PET in schizophrenia. Psychiatry Res 16:317-330

Kawasaki Y, Maeda Y, Urata K, Higashima M, Yamaguchi N, Suzuki M, Takashima T, Ide Y (1993): A quantitative magnetic resonance imaging study of patients with schizophrenia. Eur Arch Psychiatry Clin Neurosci 242: $268-272$

Kelsoe JR, Cadet J, Pickar D, Weinberger DR (1988): Quantitative neuroanatomy in schizophrenia. Arch Gen Psychiatry 45:533-541
Kishimoto J, Kuwahara H, Ohno H, Takazu O, Hama Y, Sata C, Ishii T, Nomura Y, Fujita H, Miyauchi T, Matsushita M, Yokoi S, Lio M (1987): Three subtypes of chronic schizophrenia identified using [C-11]-glucose positron emission tomography. Psychiatry Research 21:285-292

Lee G, Loring D, Flanigin HF, Smith J, Meador K (1988): Electrical stimulation of the human hippocampus procedures verbal intrusion during memory testing. Neuropsychologia, 26:623-627

Lewis DA, Foote SL, Goldstein M, Morrison JH (1988): The dopaminergic innervation of monkey prefrontal cortex: A tryosine hydroxylase immunohistochemical study. Brain Res 449:225-243

Liddle PF, Friston KJ, Frith CD, Hirsch SR, Jones T, Frackowiak (1992): Patterns of cerebral blood flow in schizophrenia. Br J Psychiatry 160:179-186

Marsh L, Suddath RL, Higgins N, Weinberger DR (1994): Medial temporal lobe structures in schizophrenia: Relationship of size to duration of illness. Schizophr Res 11: 225-238

Matsui T, Hirano A (1978): An Atlas of the Human Brain for Computerized Tomography. New York, Igaku-Shoin Medical Publishers

Mathew RJ, Wilson WH, Tant SR, Robinson L, Prakash R (1988): Abnormal resting regional cerebral blood flow patterns and their correlates in schizophrenia. Arch Gen Psychiatry 45:542-549

Musalek M, Podreka I, Walter H, Suess E, Passweg V, Nutzinger D, Strobl R, Lesch OM (1989): Regional brain function in the hallucinations: A study of regional cerebral blood flow with $99 \mathrm{~m}$-Tc-HMPAO-SPECT in patients with auditory hallucinations, tactili hallucinations, and normal controls. Compr Psychiatry 30:99-108

Overall JE, Gorham DR (1962): The Brief psychiatric rating scale. Psychol Rep 10:799-812

Overall JE, Gorham DR (1976): Brief psychiatric rating scale, In Guy W (Ed) ECDEU Assessment Manual for Psychopharmacology, revised edition, Rockville, Maryland: 157-169

Pardo JV, Pardo PJ, Janer KW, Raichle ME (1990): The anterior cingulate cortex mediates processing selection in the Stroop attentional conflict paradigm. Proceedings NAS 87:256-259

Petersen SE (1993): The processing of single words studied with positron emission tomography. Annu Rev Neurosci 16:509-530

Phelps ME, Huang SC, Hoffman EJ, Selin C, Sokoloff L, Kuhl DE (1979): Tomographic measurement of local cerebral glucose metabolic rate in humans with $[\mathrm{F}-18]$ 2-fluoro-2deoxy-D-glucose: Validation of method. Ann Neurol 6: $371-388$

Phelps ME, Mazziotta J, Schelbert HR, eds. (1986): Positron Emission Tomography and Autoradiography: Principles and Applications for the Brain and Heart. New York, Raven Press

Reivich M, Alavi A, Fowler J, Russell J, Arnett C, MacGregor RR, Shiue CY, Atkins H, Anand A, Dann R, Greenberg $\mathrm{JH},(1985)$ : Glucose metabolic rate kinetic model parameter determination in humans: The lumped constant and rate constants for [F-18] fluorodeoxyglucose. J Cereb Blood Flow Metab 5:179-192 
Rossi A, Stratta P, Mancini F, et al. (1994): Magnetic resonance imaging findings of amygdala-hippocampus shrinkage in male patients with schizophrenia. Psychiatry Res 52: 43-53

Starkstein SE, Vasquez S, Petracca G (1994): A SPECT study of delusions in Alzheimer's disease. Neurology 44:20552059

Shenton ME, Kikinis R, Jolesz FA, Pollak SD, LeMay M, Wibble CG, Hokama H, Martin J, Metcalf D, Coleman M, McCarley RW (1992): Abnormalities of the left temporal lobe and thought disorders in schizophrenia. N Engl J Med 327:604-612

Sheppard G, Grunzelier J, Manchanada R, Hirsh SR, Wise R, Frackowiack R, Jones T (1983): [O-15]-Positron emission tomographic scanning in predominantly never-treated acute schizophrenic patients. Lancet 2:1448-1452

Siegel BV, Buchsbaum MS, Bunney WE, Gottschalk LA, Haier RJ, Lottenberg S, Nafaji A, Neuchterlein KH, Potkin SG, Wu JC (1993): Cortical-striatal-thalamic circuits and brain glucose metabolic activity in 70 unmedicated male schizophrenic patients. Am J Psychiatry 150:13251336

Sokoloff L, Reivich M, Kennedy C, Des Rosiers MH, Patlak CS, Pettigrew KD, Sakurada O, Shinohara M (1977): The [C-14] deoxyglucose method for the measurement of local cerebral glucose utilization: Theory, procedure, and normal values in the conscious and anesthetized albino rat. J Neurochem 28:897-916

Spielberger CD, Gorsuch RL, Lushene RE (1970): Manual for the State-Trait Anxiety Inventory. Palo Alto, CA, Consulting Psychologists Press

Spitzer RL, Williams JBW, Gibbon M, First MD (1989): Structured Clinical Interview for DSM-III-R. Biometrics Research Division, New York State Psychiatric Institute

Squire LR (1987): Memory and Brain. New York, Oxford University Press

Suddath RL, Casanova MF, Goldberg TE, Danile DG, Kelsoe JR, Weinberger DR (1989): Temporal lobe pathology in schizophrenia. Am J Psychiatry 146:464-472
Suddath RL, Christison GW, Torrey EF, Casanova MF, Weinberger DR (1990): Anatomical abnormalities in the brains of monozygotic twins discordant for schizophrenia. N Engl J Med 322:789-794

Tamminga CA, Thaker GK, Buchanan R, Kirkpatrick B, Alphs LD, Chase TN, Carpenter WT (1992): Limbic system abnormalities identified in schizophrenia using positron emission tomography with fluorodeoxyglucose and neocortical alterations with deficit syndrome. Arch Gen Psychiatry 49:522-530

Ungerleider LG, Haxby JV (1994): "What" and "where" in the human brain. Curr Opin Neurobiol 4:157-165

Valk PE, Jagust WI, Derenzo SE, Huesman RH, Geyer AB, Budinger TF (1990): Clinical evaluation of a high resolution $(2.6-\mathrm{mm})$ positron emission tomograph. Radiology 196:783-790

Waddington J (1993): D1:D2 Dopamine Receptor Interactions: Neuroscience and Psychopharmacology. San Diego, CA, Academic Press

Wilson WH, Mathew RJ (1993): Asymmetry of rCBF in schizophrenia: Relationship to AP-gradient and duration of illness. Biol Psychiatry 33:806-814

Wolkin A, Jaeger J, Brodie JD, Wolf AP, Fowler J, Rotrosen J, Gomez-Mont F, Cancro R (1985): Persistence of cerebral metabolic abnormalities in chronic schizophrenia as determined by positron emission tomography. Am J Psychiatry 142:564-571

Young AH, Blackwood DH, Roxborough H, McQueen JK, Martin MJ, Kean D (1991): A magnetic resonance imaging study of schizophrenia: Brain structure and clinical symptoms. Br J Psychiatry 158:158-164

Zipursky RB, Marsh L, DeMent S, Shear PK, Sullivan EV, Murphy GM, Csernansky JG, Pfefferbaum A (1994): Volumetric MRI assessment of temporal lobe structures in schizophrenia. Biol Psychiatry 35:501-516

Zipursky RB, Lim KO, Sullivan EV, Brown BW, Pfefferbaum (1992): A widespread cerebral gray matter volume deficits in schizophrenia. Arch Gen Psychiatry 49:195-205 